\title{
Editorial
}

\section{Statistics and Applied Probability: A Tribute to Jeffrey J. Hunter}

\author{
Paul Cowpertwait, Graeme Wake, Robert D. Anderson, \\ Howard Edwards, and Shayle Searle
}

Received 16 September 2007; Accepted 16 September 2007

Copyright () 2007 Paul Cowpertwait et al. This is an open access article distributed under the Creative Commons Attribution License, which permits unrestricted use, distribution, and reproduction in any medium, provided the original work is properly cited.

We are delighted to be associated as guest editors with the publication of this special issue of the Journal of Applied Mathematics and Decision Sciences, in honour of our esteemed colleague Professor Jeffrey J. Hunter. This special issue marks Jeff's retirement from Massey University, although Jeff plans to continue his research. It also acknowledges Jeff's many contributions to probability and statistics over a long career of 40 -plus years, during which he has served his colleagues and university exceedingly well, with the utmost integrity, and has served and promoted his academic discipline in a consistent and highly professional

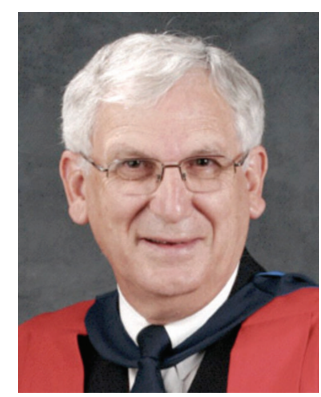
manner, representing the interests of the statistics discipline in many capacities and roles. We have been honoured to have him as a colleague, and given the impressive response of the authors of this issue, we believe this feeling is shared by many in the academic community. Some personal notes from Robert Anderson (Pro Vice-Chancellor of the College of Sciences, Massey University), Howard Edwards (Programmes Director in the College of Sciences), and Emeritus Professor Shayle Searle are included in this editorial.

We are indebted to the Hindawi Publishing Corporation for supporting this initiative, and for their efficient handling of the manuscripts. We thank Tony Norris (Head of our Institute) and Robert McKibbin (former Head) for their helpful suggestions and moral support, and are grateful to Tony and Gaven Martin, for providing financial support via 
the institute and personal research funds, respectively, without which this publication would not have been possible. Helpful comments from Stephen Haslett are acknowledged. We thank the many referees who helped tremendously with the reviewing process; in particular, we acknowledge the following referees for their helpful comments and/or detailed reviews: Tasos Tsoularis, Martin Hazelton, Valerie Isham, Beatrix Jones, Claire Jordan, Dominic Lee, Michael Leonard, Barry McDonald, Andrew Metcalfe, Christian Onof, Marco Reale, Danny Walsh, and Thomas Yee. Finally, we thank the authors, many of whom know Jeff well and are his friends; we are very grateful to them for their impressive response to this special issue and for their comments on each others work, which has helped ensure that this publication is of high standard.

Paul Cowpertwait and Graeme Wake

Guest Co-Editors

July, 2007

\section{Professor Jeffrey J. Hunter, FNZMS by Robert D. Anderson, Pro Vice-Chancellor}

It is an honour to have been asked to contribute some thoughts on Professor Jeffrey Hunter to this special publication.

I first met Jeff at the time of his interview for the Chair in Statistics at Massey University, in 1990. In the subsequent 17 years, we have developed a strong personal and professional friendship. Such is his instinctively generous and helpful nature, it is impossible not to enjoy, and value, his friendship and professional interaction. He has been an outstanding colleague and mentor to many.

When one reflects on Jeff's career and achievements, a remarkable aspect that stands out, and that others rarely emulate, is that at varying times he has held some high-level managerial posts, the Foundation Deanship of the Faculty of Information and Mathematical Sciences at Massey University for example, yet he still managed to sustain an enviable personal record of research and advanced scholarship-compared to most other university administrators. The award of a Doctor of Science degree by Massey University in 2005 is compelling evidence of enduring scholarship at the highest level. The New Zealand Statistical Association Campbell Award (its highest) in 2006 for "contributions to statistical research and education, and services to the profession of statistics" further reflects his ability to keep his managerial responsibilities-without exception, successfully discharged-in perspective in order that he could find time to concentrate on what actually counts in any university of substance, namely; advanced education and scholarship.

In the early stages of our association, Jeff and I were fellow Deans. Later when the Institute of Information and Mathematical Sciences, based at the Auckland Campus of Massey University, was founded, the wider College of Sciences needed to find a leader with an ability to inspire, and to organise, others to commit to a shared vision for a newly created multidisciplinary entity. Fortunately, Jeff was available for the role and (with high probability of success-that particular word needs to appear in any statement about him) he was appointed Foundation Head as from 1st January, 1998. It is important for the formal record that appreciation be expressed for his excellent leadership of the institute over those formative years. 
Paul Cowpertwait et al. 3

It is entirely apt that there is a dedicated publication honouring Professor Jeffrey Hunter's outstanding career of advanced scholarship in statistics and mathematics.

Robert D. Anderson, ONZM

Pro Vice-Chancellor (Sciences)

July, 2007

\section{Jeff Hunter's Contribution to Statistics at Massey University by Howard Edwards}

It has been my great pleasure to work under and with Jeff Hunter in his variety of roles at Massey University: Professor and Head of the Statistics Department at Palmerston North, Dean of the Faculty of Information and Mathematical Sciences which spanned both the Palmerston North campus and the new Albany campus, and Foundation Head of the Institute of Information and Mathematical Sciences based on the new Albany campus.

Jeff arrived at Massey University in 1990 after an already distinguished career at the University of Auckland. At the time, the Statistics Group within the combined Department of Mathematics and Statistics at Massey had recently tried to break away and form a separate department but had been unsuccessful in this regard. Jeff recognised that Statistics as a discipline within the university would only receive its proper recognition and grow if it were a separate department and argued accordingly for this, within a larger grouping of departments, including that of Mathematics. Under his leadership a de facto department was effectively created, and the university recognised this in 1991 with the establishment of the Department of Statistics.

Jeff's background in applied probability led some to worry that he might alter the applied focus of statistics at Massey. However, Jeff always put the interests of the statisticians as a group first, and the subject flourished as a result of judicious staff appointments through the early 1990s.

In 1993, Massey University opened its new Albany campus at Auckland and Jeff was fully supportive of the small Statistics group (consisting of Denny Meyer, Barry McDonald, and myself) that was set up there in 1994 to support the offerings in Business and in Information Sciences. The campus grew swiftly and so did the group, and when the Faculty of Information and Mathematical Sciences went out of existence as part of university restructuring in 1997 Jeff was appointed as Foundation Head of the Institute of Information and Mathematical Sciences which was (and continued to be) based on the Albany campus. Both Statistics in particular and Information Sciences in general flourished under Jeff's leadership, and when Jeff stepped down as Head in 2002, he continued to lead the Statistics group at Albany.

Those of us who have been part of Statistics at Massey University have been fortunate to benefit from Jeff's leadership, vision, and collegiality over the past 17 years, and we owe him a huge debt of thanks in making Statistics the success it is at Massey University.

Howard Edwards Programmes Director for Information Sciences 


\section{A Personal Note to Jeff J. Hunter on His Retirement by Shayle Searle}

What would mathematically bring together a Markov chain enthusiast and a linear models devotee? The link for Jeff and me is generalized inverse matrices. And it is of no small importance that we are also both New Zealanders each with an off-shore Ph.D., both enjoy travel and for more than twenty years have had much pleasure in being guests in each other's homes. For a variety of reasons, some legitimate and some patently transparent, I have been fairly inactive statistically since retiring twelve years ago. Hence, I cannot, in the time made available to me, offer anything new, as much as I would like to be in a position to do so. Retirement for me has been, and is, a delight, especially for relaxingly doing things other than statistics. I sincerely hope that my good friend Jeff and his wife Hazel get the same pleasure from it as I do. All good wishes to you both.

Emeritus Professor Shayle Searle April, 2007

Paul Cowpertwait: Institute of Information and Mathematical Sciences, College of Sciences, Massey University, Auckland, New Zealand

Email address: p.s.cowpertwait@massey.ac.nz

Graeme Wake: Institute of Information and Mathematical Sciences, College of Sciences, Massey University, Auckland, New Zealand

Email address: g.c.wake@massey.ac.nz

Robert D. Anderson: College of Sciences, Massey University, Auckland, New Zealand Email address: r.d.anderson@massey.ac.nz

Howard Edwards: Institute of Information and Mathematical Sciences, College of Sciences, Massey University, Auckland, New Zealand

Email address: h.edwards@massey.ac.nz

Shayle Searle: Department of Biological Statistics and Computational Biology,

Cornell University, Ithaca, NY 13101, USA

Email address: srs24@cornell.edu 


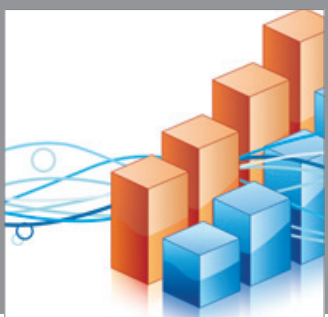

Advances in

Operations Research

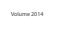

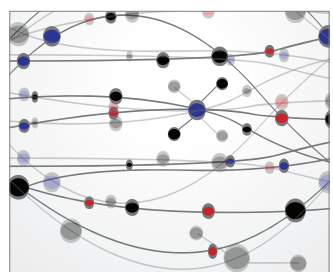

\section{The Scientific} World Journal
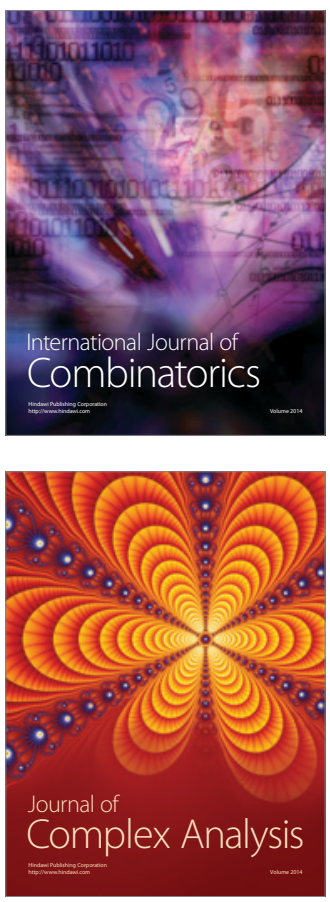

International Journal of

Mathematics and

Mathematical

Sciences
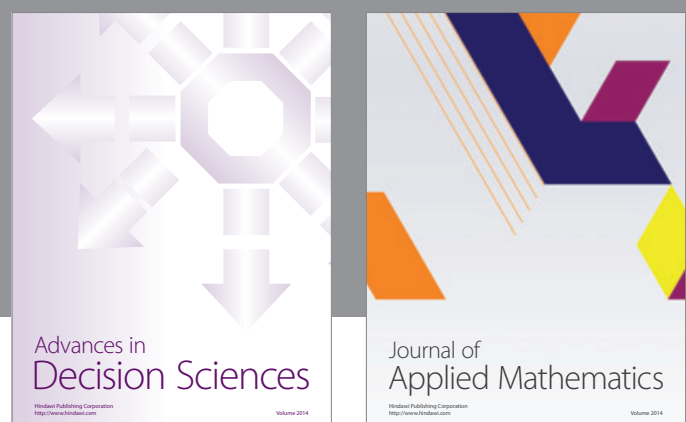

Journal of

Applied Mathematics
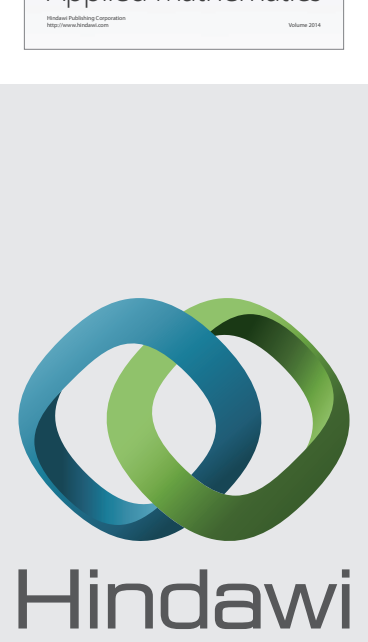

Submit your manuscripts at http://www.hindawi.com
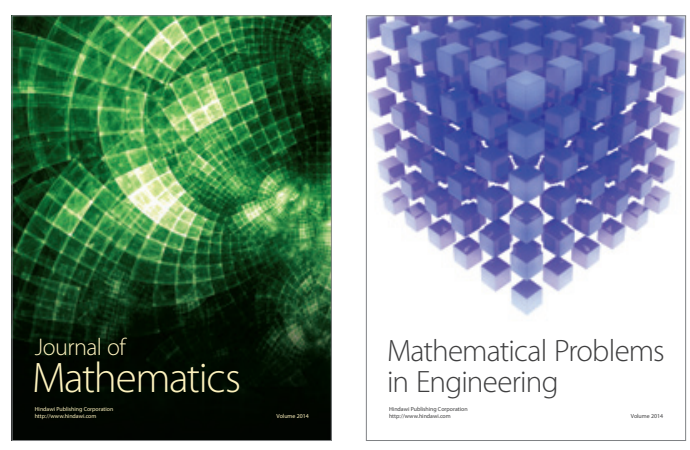

Mathematical Problems in Engineering
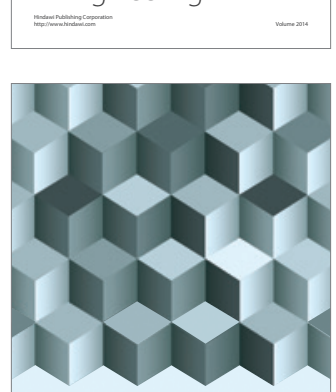

Journal of

Function Spaces
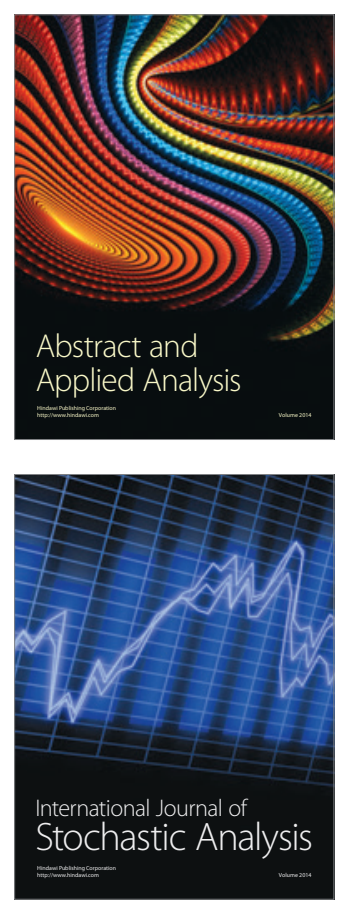

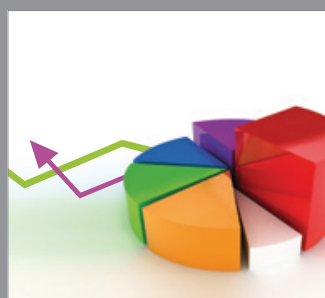

ournal of

Probability and Statistics

Promensencen
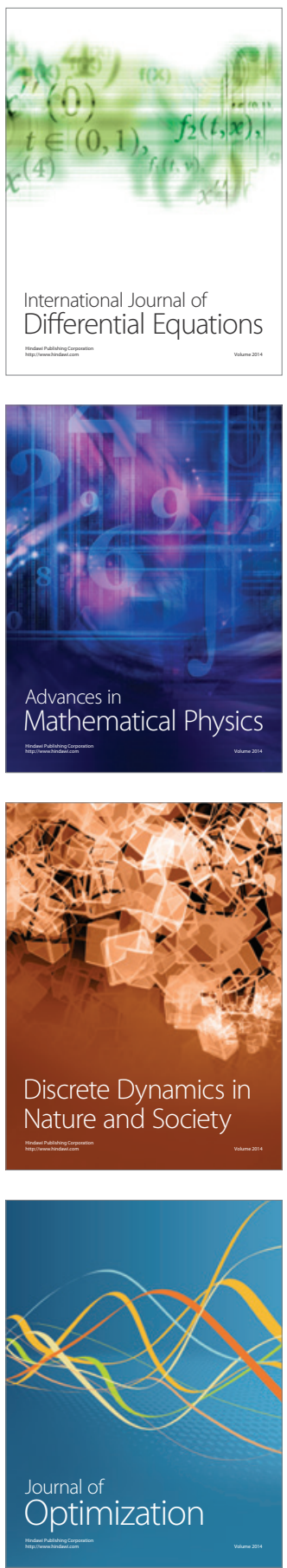